\title{
Fatigue characteristics on dialysis and non- dialysis days in patients with chronic kidney failure on maintenance hemodialysis
}

Subrata Debnath ${ }^{1 *}$, Rain Rueda ${ }^{2}$, Shweta Bansal ${ }^{1}$, Balakuntalam S. Kasinath ${ }^{1}$, Kumar Sharma ${ }^{1}$ and Carlos Lorenzo ${ }^{3}$

\begin{abstract}
Background: Fatigue is prevalent in hemodialysis patients who for survival follow a strict dialysis treatment regimen - dialysis and non-dialysis days. As a result, the daily activities, symptom burden, and clinical outcomes of hemodialysis patients vary significantly between dialysis and non-dialysis days. Fatigue is one of the most reported debilitating symptoms by hemodialysis patients with profound negative impact on their quality of life. Prior studies assessed fatigue during the preceding 7 or 30 days and did not discriminate fatigue characteristics between dialysis and non-dialysis days. We aimed to characterize and compare fatigue severity and fatigue interference with daily activities between dialysis and non-dialysis days.
\end{abstract}

Methods: Hemodialysis patients self-reported fatigue on consecutive dialysis and non-dialysis days using the 9-item Brief Fatigue Inventory. The differences in fatigue characteristics between dialysis and non-dialysis days were analyzed using one-way ANCOVA.

Results: Global fatigue burden was worse on a dialysis day compared to a non-dialysis day ( $P$ for all $<0.001)$. Age and education were associated with fatigue, but hemodialysis-related variables were not. A significant inverse association of physical activity with fatigue severity observed on non-dialysis day; there was also a negative association between the normalized protein catabolic rate and fatigue severity on both dialysis and non-dialysis days. The positive association of depression with fatigue severity and fatigue interference were consistent on both dialysis and non-dialysis days. None of these factors, however, explained differences in fatigue characteristics between dialysis and non-dialysis days.

Conclusions: Fatigue, measured in severity and interference, was more pronounced on a dialysis day relative to a non-dialysis day. These differences were not explained by age, sex, education, hemodialysis-related variables, habitual exercise, nutritional status, and or depression. The quantitative measures of fatigue characteristics may facilitate future interventional trials design and better fatigue management for hemodialysis patients.

Keywords: Fatigue, Severity, Interference, Dialysis day, Non-dialysis day

\footnotetext{
*Correspondence: nath@uthscsa.edu

'Division of Nephrology, Department of Medicine, University of Texas Health San Antonio, 7703 Floyd Curl Dr, San Antonio, TX, USA

Full list of author information is available at the end of the article
}

(c) The Author(s). 2021 Open Access This article is licensed under a Creative Commons Attribution 4.0 International License, which permits use, sharing, adaptation, distribution and reproduction in any medium or format, as long as you give appropriate credit to the original author(s) and the source, provide a link to the Creative Commons licence, and indicate if changes were made. The images or other third party material in this article are included in the article's Creative Commons licence, unless indicated otherwise in a credit line to the material. If material is not included in the article's Creative Commons licence and your intended use is not permitted by statutory regulation or exceeds the permitted use, you will need to obtain permission directly from the copyright holder. To view a copy of this licence, visit http://creativecommons.org/licenses/by/4.0/ The Creative Commons Public Domain Dedication waiver (http://creativecommons.org/publicdomain/zero/1.0/) applies to the data made available in this article, unless otherwise stated in a credit line to the data. 


\section{Background}

Kidney failure patients on maintenance hemodialysis treatment endure multitude of symptoms and rank fatigue as one of the most dreadful symptoms which adversely affects their daily activities and quality of life [1-4]. These patients prioritize relief of fatigue over survival $[2,5]$. For survival, hemodialysis patients follow a strict weekly treatment regimen - either MondayWednesday-Friday or Tuesday-Thursday-Saturday are dialysis days (treatment days) and remaining days are non-dialysis days (non-treatment days). Due to such unique and restrictive life pattern, the daily activities, symptom burden, and clinical outcomes of hemodialysis patients vary significantly between dialysis and nondialysis days. For example, hemodialysis patients consume remarkably lower dietary energy and protein, experience diminished mood and impaired cognitive function, and report worse subjective well-being on dialysis days compared to non-dialysis days [6-8]. Studies also showed higher relative risks for mortality on dialysis days compared to non-dialysis days [9]. However, little is known about the fatigue characteristics and magnitude of fatigue burden on dialysis and non-dialysis days.

Prior studies measured fatigue over the preceding week or month [10]. Diurnal fatigue course and pattern over days have also been reported [11, 12]. However, these studies did not discriminate the characteristics of fatigue between dialysis and non-dialysis days. Fatigue severity and the pervasive impact of fatigue on life participation are the two most important dimensions of fatigue $[10,13]$. The differences in fatigue severity and fatigue interference with daily activities, mood, relations with family and friends, life enjoyment, etc. between dialysis and non-dialysis days have not been well characterized. The magnitude of global fatigue burden on dialysis and non-dialysis days is also unknown.

Contemporary reports emphasize such knowledge gap and critically advocate for more explicit research geared toward a better understanding of fatigue [14-16]. Elucidating the difference of fatigue on both dialysis and nondialysis days may help design future research studies and clinical trials to implement targeted and timely intervention to mitigate fatigue burden. Therefore, the purpose of this study was to characterize and compare day-today fatigue severity and fatigue interference with daily activities in hemodialysis patients.

\section{Methods}

\section{Study design and population}

This observational study enrolled clinically stable prevalent hemodialysis patients treated at two in-center dialysis clinics with following eligibility criteria: (i) on thrice weekly hemodialysis dialysis for at least six months; and (ii) without clinical or laboratory diagnosis of malnutrition and anemia, acute cardiovascular events requiring hospitalization, and comorbidities such as active malignant cancer, refractory psychiatric disorders, and significant neurological disorders. All patients received standard management for hemodialysis and comorbidities as per the recommended guidelines. Each patient was dialyzed for an average of $4 \mathrm{~h}$ with high-flux polysulfone dialyzers using bicarbonate based dialysate. The study was approved by the local Institutional Review Board and all participants provided written informed consent prior to the study procedures.

\section{Measurements \\ General measurements}

Patients' medical charts were reviewed to obtain routine dialysis day blood chemistry values and dialysis parameters including dialysis adequacy measure, i.e., Kt/V. Body weight and blood pressure values were collected on a dialysis day at two time points - at the beginning and end of the dialysis session. To minimize variabilities, all study procedures were performed during the mid-week hemodialysis treatment.

A self-administered questionnaire was utilized to collect socio-demographic data on ethnicity, educational attainment, and employment status. In addition, selfreported weekly time spent on physical activities was recorded. To assess depression, a 21-item Beck Depression Inventory (BDI)-II was administered on a dialysis day [17]. The BDI-II assesses symptoms of depression during the past two weeks. Each BDI-II item represents a symptom with a scale value of 0 (no symptom) to 3 (severe symptom) and summing the total scores range from 0 to 63 - higher scores represent more severe depression [17]. BDI-II is an extensively validated and widely used depression screening instrument in hemodialysis patients [18].

\section{Brief Fatigue Inventory}

The Brief Fatigue Inventory (BFI) [19] was used to document self-reported fatigue. During a mid-week dialysis session, each participant received two sets of BFI - one marked with "Dialysis Day" and the other with "Nondialysis Day" for treatment and non-treatment day, respectively. Each participant completed the "Dialysis Day" BFI within the first hour of dialysis session. The "Non-dialysis Day" BFI was completed on the following day within the same timeframe - approximately $24 \mathrm{~h}$ later. Depending on the day (dialysis or non-dialysis), fatigue reporting time for all nine BFI items was fixed to the specific day [19]. BFI was not administered to capture fatigue immediately after dialysis session. The first three BFI items measure fatigue severity level on a $0-10$ scale with score ranging from 0 (no fatigue) to 10 (fatigue as bad as you can imagine). The BFI item \#3 
"fatigue worst" score can be utilized to classify 'severe fatigue' (score of $\geq 7$ ) and 'non-severe fatigue' (score of $<7$ ) for conceptual simplicity [19]. The remaining six BFI items assess fatigue interference in relation to patients' general activity, mood, walking ability, normal work (both indoor and outdoor), relations with other people, and enjoyment of life on a $0-10$ numerical rating scale, with 0 being "does not interfere" and 10 being "completely interferes." The arithmetic means of the first three and last six BFI items were used to define fatigue severity and fatigue interference score, respectively. The arithmetic mean of the nine BFI items was used as a global fatigue score. BFI has been extensively validated in cancer patients [19] and used in hemodialysis patients [20].

\section{Statistical analysis}

Fatigue scores on a dialysis day were compared to those on a non-dialysis day using one-way ANCOVA in order to account for the effect of relevant socio-demographic, laboratory, and dialysis parameters. We also assessed the influence of dietary protein on fatigue, estimated by the normalized protein catabolic rate (nPCR), which is often used as a measure of habitual dietary protein intake and normalized to the patient's body weight [21, 22]. We used following formula to calculate nPCR [23]:

$\mathrm{nPCR}$, in $\mathrm{g} / \mathrm{kg}$ per day $=0.22+\frac{(0.036 \times \text { intradialytic rise in blood urea nitrogen } \times 24)}{\text { intradialytic interval (hours })}$

Pearson correlation coefficient was used to examine the strength of the relationship of fatigue scores between dialysis and non-dialysis days, and the relationship of socio-demographic, exercise, nPCR, laboratory variables, dialysis parameters, and BDI-II scores with fatigue scores on both dialysis and non-dialysis days.

Variables that were associated with fatigue were used as covariates in analysis that examined fatigue differences between dialysis and non-dialysis days. We used one-way ANCOVA to assess differences in fatigue severity, fatigue interference, and global fatigue between dialysis and non-dialysis days in order to account for the effect of variables that were associated with fatigue. Among the covariates, age, exercise, nPCR, and BDI-II score were used as continuous variables. All analyses were performed using the SAS (version 9.4, SAS Institute Inc., Cary, NC). A two-sided $P$ value $<0.05$ was considered statistically significant.

\section{Results}

\section{Population characteristics}

Of total 209 maintenance hemodialysis patients from two in-center dialysis centers, 127 met the study eligibility criteria and 115 provided written consent to participate in the study. The characteristics of the study participants are shown in Table 1 . The mean age was
Table 1 Characteristics of the study participants, $n=115$

\begin{tabular}{|c|c|}
\hline Variable & \\
\hline Age, yr & $54.8 \pm 12.8$ \\
\hline Female, \% & 47.8 \\
\hline \multicolumn{2}{|l|}{ Education (\%) } \\
\hline$\leq 8$ th grade & 33.3 \\
\hline 9th grade to $\leq$ high school & 19.3 \\
\hline High school diploma & 32.5 \\
\hline Vocational school or some college & 11.4 \\
\hline Bachelor degree & 2.6 \\
\hline Graduate degree & 0.9 \\
\hline Exercise (min/week) & $59.8 \pm 87.6$ \\
\hline Pre-dialysis body weight, kg & $81.64 \pm 20.66$ \\
\hline Pre-dialysis body mass index, $\mathrm{kg} / \mathrm{m}^{2}$ & $31.07 \pm 7.70$ \\
\hline Pre-dialysis systolic blood pressure, $\mathrm{mmHg}$ & $151.11 \pm 26.94$ \\
\hline Pre-dialysis diastolic blood pressure, $\mathrm{mmHg}$ & $71.43 \pm 15.40$ \\
\hline Dialysis adequacy (Kt/N) & $1.84 \pm 0.38$ \\
\hline Duration of dialysis, months & $56.76 \pm 39.60$ \\
\hline Normalized protein catabolic rate, $\mathrm{g} / \mathrm{kg}$ per day & $1.03 \pm 0.30$ \\
\hline Blood urea nitrogen, mg/dL & $53.09 \pm 14.41$ \\
\hline Serum albumin, g/dL & $3.46 \pm 0.38$ \\
\hline Phosphorus, mg/dL & $5.33 \pm 1.61$ \\
\hline Hemoglobin A1c, \% & $6.93 \pm 1.86$ \\
\hline Hemoglobin, gm/dL & $11.04 \pm 1.43$ \\
\hline Hematocrit, \% & $34.55 \pm 4.22$ \\
\hline Intact parathyroid hormone, $\mathrm{pg} / \mathrm{mL}$ & $332.24 \pm 324.05$ \\
\hline Vitamin $\mathrm{D}, \mathrm{pg} / \mathrm{mL}$ & $45.17 \pm 25.74$ \\
\hline
\end{tabular}

"Data are mean \pm standard deviation, or $n(\%)$

$54.8 \pm 12.8$ years and $47.8 \%$ were female. The mean serum albumin, nPCR, and blood hemoglobin levels of the study participants were $3.46 \pm 0.38 \mathrm{~g} / \mathrm{dl}, 1.03 \pm 0.30 \mathrm{~g} /$ $\mathrm{kg} /$ day, and $11.04 \pm 1.43 \mathrm{~g} / \mathrm{dl}$, respectively. The primary etiology of kidney failure for all subjects was type 2 diabetes and the mean hemoglobin A1c of the study patients was $6.93 \pm 1.86 \%$.

Characteristics of fatigue on dialysis and non-dialysis days Fatigue severity and fatigue interreference scores on both dialysis and non-dialysis days are presented in Table 2. The unadjusted mean scores for fatigue now, usual, and worst were all remarkably higher on a dialysis day compared to a non-dialysis day. Fatigue severity level (mean of first 3 BFI items scores) was significantly pronounced on a dialysis day compared to a non-dialysis day, $5.35 \pm 2.50$ and $3.47 \pm 2.85, P<0.0001$, respectively (Table 2). Prevalence of severe fatigue (defined as BFI item \#3 “fatigue worst" score $\geq 7$ ) is displayed in Fig. 1. 
Table 2 Fatigue characteristics on dialysis and non-dialysis days

\begin{tabular}{|c|c|c|c|c|c|}
\hline Fatigue characteristics & Dialysis Day & Non-dialysis Day & $P^{*}$ & $P^{* *}$ & $P^{* * *}$ \\
\hline \multicolumn{6}{|l|}{ Severity } \\
\hline Fatigue (weariness, tiredness) NOW & $4.39 \pm 2.75$ & $3.23 \pm 2.86$ & 0.003 & 0.001 & 0.002 \\
\hline USUAL level of fatigue (weariness, tiredness) & $5.21 \pm 3.03$ & $3.23 \pm 2.86$ & $<0.0001$ & $<0.0001$ & $<0.0001$ \\
\hline WORST level of fatigue (weariness, tiredness) & $6.36 \pm 2.75$ & $3.96 \pm 3.11$ & $<0.0001$ & $<0.0001$ & $<0.0001$ \\
\hline \multicolumn{6}{|l|}{ Interference: fatigue interfered with } \\
\hline General activity & $5.14 \pm 3.05$ & $2.88 \pm 2.87$ & $<0.0001$ & $<0.0001$ & $<0.0001$ \\
\hline Mood & $4.65 \pm 3.07$ & $2.97 \pm 3.09$ & $<0.0001$ & $<0.0001$ & $<0.0001$ \\
\hline Walking ability & $4.67 \pm 3.27$ & $3.53 \pm 3.35$ & 0.01 & 0.01 & 0.025 \\
\hline Normal work (includes both work outside the home and daily chores) & $4.79 \pm 3.09$ & $3.35 \pm 3.24$ & 0.001 & 0.0006 & 0.0011 \\
\hline Relations with other people & $3.83 \pm 3.39$ & $2.75 \pm 3.26$ & 0.02 & 0.01 & 0.024 \\
\hline Enjoyment of life & $4.68 \pm 3.41$ & $3.23 \pm 3.43$ & 0.002 & 0.001 & 0.001 \\
\hline \multicolumn{6}{|l|}{ Mean score } \\
\hline Fatigue level (severity) & $5.35 \pm 2.50$ & $3.47 \pm 2.85$ & $<0.0001$ & $<0.0001$ & $<0.0001$ \\
\hline Fatigue interference & $4.55 \pm 2.65$ & $3.14 \pm 2.92$ & 0.0005 & 0.0002 & 0.0002 \\
\hline Global fatigue & $4.82 \pm 2.43$ & $3.25 \pm 2.80$ & $<0.0001$ & $<0.0001$ & $<0.0001$ \\
\hline
\end{tabular}

Data are mean \pm standard deviation

* Unadjusted

${ }^{* *}$ Adjusted for age, sex, education, dialysis day, dialysis shift (morning, afternoon, or evening), and duration on hemodialysis

${ }^{* * *}$ Adjusted also for exercise, depression, and nPCR

Similar trend was noted for fatigue interference items with life participations (Table 2). Among these, impact of fatigue on general activity and mood were strikingly higher on a dialysis day compared to a non-dialysis day, $P$ for both $<0.0001$. Fatigue severity (mean score of last 6 BFI items) on hemodialysis patients' daily life activities was more severe $(P=0.0002)$ on a dialysis day relative to a non-dialysis day. Dialysis and non-dialysis fatigue severity, fatigue interference, and global fatigue burden are presented in Fig. 2.

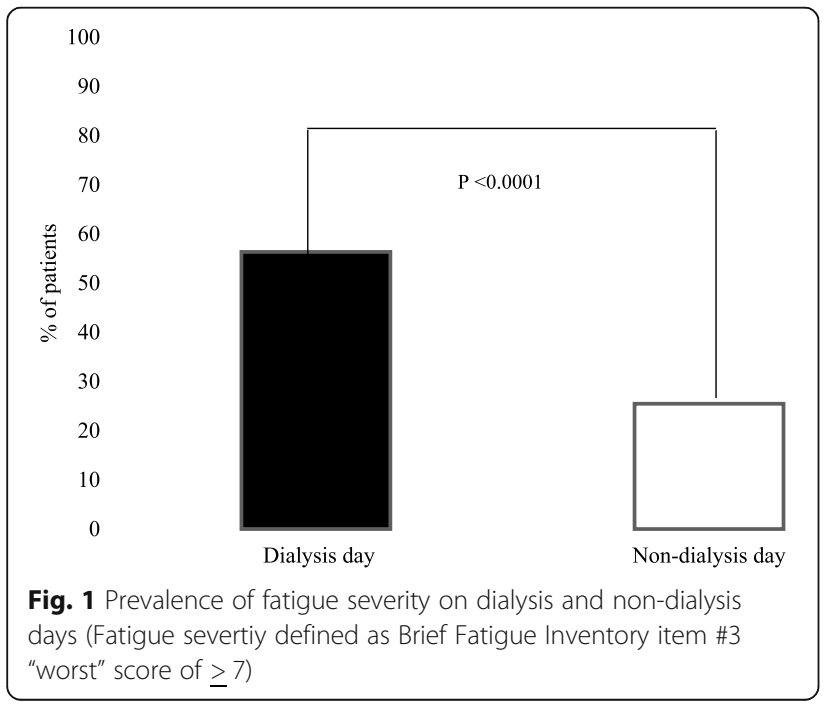

\section{Univariate analysis for correlates of fatigue characteristics} on dialysis and non-dialysis days

Correlates of fatigue were examined in order to identify variables that could explain differences in fatigue between dialysis and non-dialysis days. The associations of fatigue with age, years of education, habitual physical activity or exercise, nPCR, and BDI-II scores are presented in Table 3. There was no consistent pattern of correlations observed except for BDI-II which was positively and significantly associated with fatigue severity, fatigue interference, and global fatigue burden on both dialysis and non-dialysis days.

We noted a significant inverse association of physical activity with fatigue severity and global fatigue on nondialysis day only. There was a trend towards negative association between physical activity and fatigue interference on non-dialysis day $(r=-0.25, P=0.08)$. nPCR negatively correlated with fatigue severity (both dialysis and non-dialysis days) and global fatigue burden (on dialysis day only) (Table 3). In contrast, the significant positive association of depression with fatigue severity, interference, and global fatigue burden was consistently found on both dialysis and non-dialysis days.

Pre- and post-dialysis body weight and blood pressure as well as intradialytic changes in body weight and blood pressure did not correlate with dialysis day fatigue characteristics. Likewise, dialysis vintage, dialysis adequacy or $\mathrm{Kt} / \mathrm{V}$, and routinely measured laboratory parameters including serum albumin, blood 


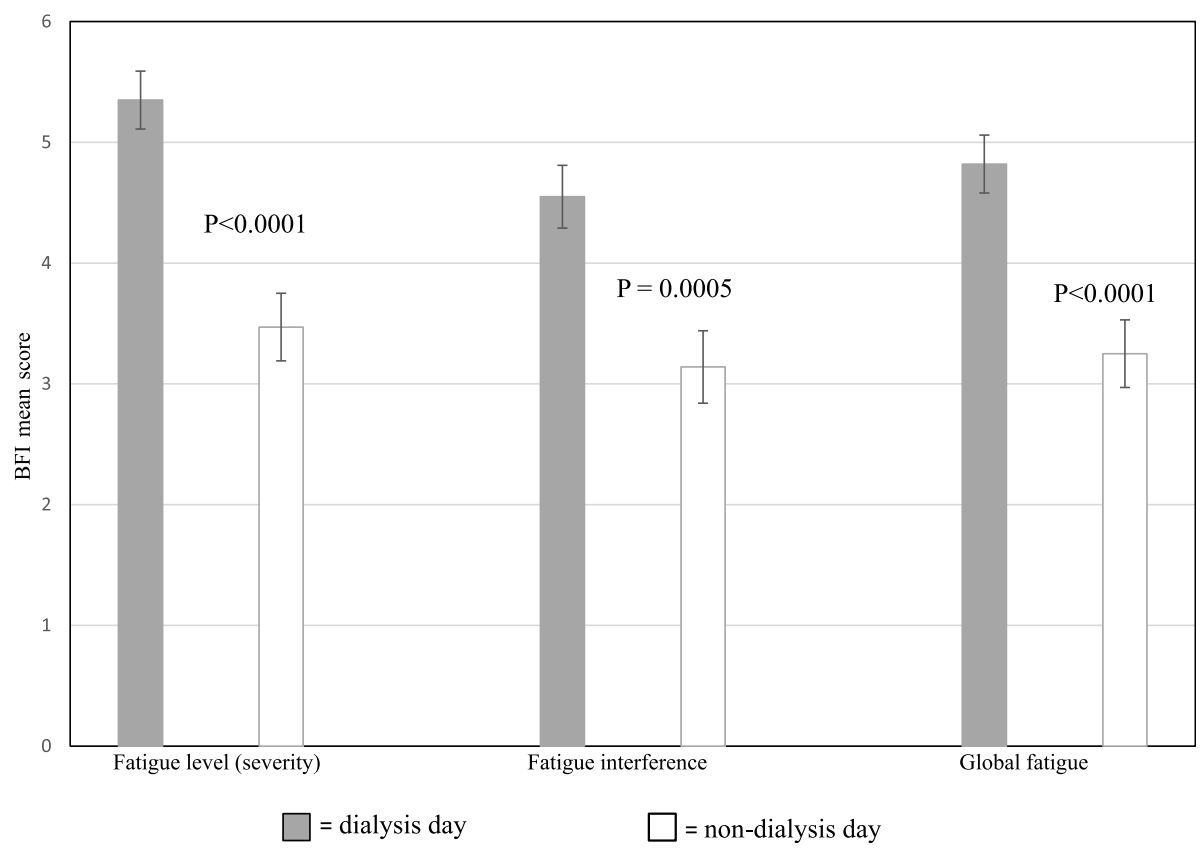

Fig. 2 Mean ( \pm SE) scores of fatigue severity, fatigue interference, and global fatigue on dialysis and non-dialysis days

hemoglobin, and vitamin $\mathrm{D}$ levels did not correlate either with dialysis day fatigue characteristics including global fatigue burden $(P$ for all $>0.05)$.

\section{Effects of factors on fatigue differences between dialysis and non-dialysis days}

Differences in significance in fatigue severity, fatigue interference, and global fatigue between dialysis and non-dialysis days did not change after the adjustment for the following potential confounding factors: age, sex, education, dialysis shift (morning, afternoon, or evening), and duration of hemodialysis dialysis. Adjustment for additional variables such as dietary protein intake as measured by nPCR, time spent on habitual physical activity, and depression symptoms did not alter the robustness in differences in fatigue scores between dialysis and non-dialysis days (Table 2).

\section{Discussion}

Fatigue severity and fatigue interference with daily activities are the two most important fatigue characteristics reported by the hemodialysis patients [13]. Our study results quantitively demonstrate that both fatigue severity and fatigue interference with daily activities are significantly greater on a dialysis day than on a non-dialysis day. Study data illustrate a high prevalence of worst fatigue on a dialysis day. The burden of global fatigue is overwhelming on a dialysis day relative to a non-dialysis day. Our analysis suggests that the factors which are associated with fatigue do not explain differences in fatigue between dialysis and non-dialysis days (Table 2).

The prevalence of fatigue has been extensively studied. However, fatigue characteristics, its determinants, and differences in fatigue characteristics between dialysis and non-dialysis days are poorly understood. Prior studies examined the 'diurnal' fatigue pattern without

Table 3 Pearson correlation coefficients relating fatigue characteristics to age, education, exercise, BDI-II, and nPCR on dialysis and non-dialysis days

\begin{tabular}{|c|c|c|c|c|c|c|}
\hline Fatigue characteristics & & Age & Education & Exercise & BDI-II & $\mathrm{nPCR}$ \\
\hline \multirow[t]{2}{*}{ Severity } & Dialysis day & $0.21^{*}$ & -0.19 & -0.21 & $0.30^{*}$ & -0.25 \\
\hline & Non-dialysis day & 0.14 & $-0.25^{*}$ & $-0.36^{*}$ & $0.43^{* *}$ & -0.24 \\
\hline \multirow[t]{2}{*}{ Interference } & Dialysis day & $0.21^{*}$ & $-0.22^{*}$ & -0.20 & $0.41^{* *}$ & -0.18 \\
\hline & Non-dialysis day & $0.28^{*}$ & $-0.22^{*}$ & -0.25 & $0.45^{* *}$ & -0.12 \\
\hline \multirow[t]{2}{*}{ Global fatigue } & Dialysis day & $0.23^{*}$ & $-0.21^{*}$ & -0.22 & $0.40^{* *}$ & -0.23 \\
\hline & Non-dialysis day & $0.24^{*}$ & $-0.24^{*}$ & $-0.29^{*}$ & $0.47^{* *}$ & -0.16 \\
\hline
\end{tabular}

$B D I-I l$ Beck Depression Inventory-II, $n P C R$ normalized protein catabolic rate

$$
{ }^{*} P<0.05
$$

${ }^{* *} P<0.0001$ 
characterizing fatigue severity and fatigue interference on dialysis and non-dialysis days. For example, one qualitative study [12] described fatigue as 'never-ending' over a 36-h period meaning fatigue persists on nondialysis day. Abdel-Kader et al. [11] documented significantly higher 'fatigue-exhaustion-feeling sleepy' symptom score on a dialysis day compared to a non-dialysis day in 55 patients using the ecological momentary assessment (EMA) method for consecutive 7 days. Recently, Brys et al. [24] employed similar EMA method to study 'fatigue course' in 51 hemodialysis patients and found that on a dialysis day fatigue increased significantly compared to a non-dialysis day; however, these studies did not examine the fatigue characteristics. Moreover, the EMA method, while appealing in certain conditions, requires significant time to complete - a major disadvantage for participants who are fatigued (e.g., hemodialysis and cancer patients) [25] and with low health literacy such as patients in our study [26]. Nevertheless, our findings of global fatigue burden on both dialysis and non-dialysis days are consistent with these prior studies.

The reason for pronounced fatigue severity and fatigue interference and overwhelming global fatigue burden on a dialysis day relative to a non-dialysis day has not been well investigated. One can postulate a number of factors (sociodemographic, lifestyle, physiological, and psychological) to explain such day-to-day fatigue variations. We noted a positive association of fatigue with age and inverse association with education which were not consistent across dialysis and non-dialysis days (Table 3). In accordance with prior studies, $[15,20,27,28]$ we did not find any association of select biochemical parameters (serum albumin, blood hemoglobin, and vitamin D) or any dialysis-related variables (changes in body weight and blood pressure) on a dialysis day with fatigue (e.g., severity and interference).

The negative association between habitual exercise or physical activity and fatigue only on non-dialysis days is not a surprising finding. Prior studies reported that hemodialysis patients are significantly less engaged in physical activities on a dialysis day compared to a nondialysis day due to several reasons - notably, lack of motivation, time commitment during dialysis days including travel to dialysis clinic, and post-dialysis fatigue [29-31]. In addition, it is likely that chronic kidney failure patients with primary etiology of diabetes suffer from multiple comorbidities such as diabetic retinopathy, peripheral neuropathy, lower limb amputation, and arthropathy which are significant barrier to physical activity [32]. Self-reported mean duration of time spent on habitual physical activity by our study participants was only about $60 \mathrm{~min}$ per week.

It is also possible that significantly lower dietary energy and protein intakes on dialysis days compared to non-dialysis days may contribute to fatigue [6]. Burrowes et al. [6] showed that both dietary energy and protein intakes were lower on dialysis day than on non-dialysis day in the Hemodialysis study patients. We found that nPCR, which is often used to evaluate habitual protein intake, [33, 34] was inversely associated with global fatigue on dialysis day and with fatigue severity on both dialysis and non-dialysis days (Table 3). These findings are consistent with results from a recent study [35]. In general, a low-protein diet may contribute to malnutrition and skeletal muscle loss resulting in poor outcomes including fatigue. The mean nPCR of our study population was $1.03 \pm 0.30 \mathrm{~g} / \mathrm{kg} /$ day (Table 1 ) which was below the optimal target of $>1.4 \mathrm{~g} / \mathrm{kg}$ per day and the Kidney Disease Outcomes Quality Initiative clinical practice guidelines recommend minimum target of $1.2 \mathrm{~g} / \mathrm{kg} /$ day $[33,34]$.

We found that depression was the only factor that correlated significantly with fatigue severity and interference on both dialysis and non-dialysis days. However, there are no comparative data available to corroborate our findings. Several studies reported significant association between fatigue and depression with moderate effect size and the nature of this relationship is yet to be elucidated $[14,36]$. There are at least two caveats to our findings. First, discrimination of fatigue and depression from each other is difficult using the currently available survey instruments because of overlapping psychological symptoms [14]. In fact, the BDI-II contains two fatigue items - loss of energy (item \#15) and tiredness (item \#20). Second, BDI-II was administered only once - on dialysis day. It could be speculated that hemodialysis patients may also experience diurnal or day-to-day variation in depression symptoms as has been reported in other patient population [37], which was not examined in the present study. Nevertheless, our observations warrant further exploration of patterns of depression using time sensitive tool on both dialysis and non-dialysis days, which could help understand the association of fatigue and depression.

It should be emphasized that the aforementioned factors (age, education, depression, exercise, and nPCR) were associated with fatigue characteristics (Table 3), but did not explain the differences in fatigue characteristics between dialysis and non-dialysis days. As can be seen from the Table 2, the unadjusted robust differences in fatigue scores between dialysis and non-dialysis days remained unchanged after adjusting for potential confounders. To our knowledge there is no comparative study available to validate our findings.

Our study has some strengths. One strength is the use of BFI. Unlike other fatigue measures, the BFI used in this study captures fatigue during the past $24 \mathrm{~h}$ or present day which is appropriate for the assessment of day-to-day fatigue variability unique to hemodialysis 
patients. In addition, BFI appears to meet the expressed recommendations of the Standardized Outcomes in Nephrology-Hemodialysis consensus workshop [13] for meaningful measurement of fatigue [38]. Of interest, the 3-question SONG-HD Fatigue Instrument [39], published recently, captures fatigue during the past week, missing unique day-to-day fatigue variations. It should also be noted that SONG-HD Fatigue Instrument has not been tested in US hemodialysis patients - the outcomes and mortality of whom are significantly different than that of Australia or United Kingdom [40]. Another strength is that our study patients were homogenous with regard to the primary etiology of kidney failure. The lack of heterogeneity of our sample population may have reduced the impact of particular disease-related factors on the results [41]. There are some limitations to this study as well. First, the sample size of the study was relatively modest. Second, homogenous patient population may limit the generalizability of the study findings. Third, we acknowledge that the correlations between fatigue and some modifiable variables (e.g., habitual exercise and protein intake) were modest and not consistent on both dialysis and non-dialysis days. Since we did not assess daily differences in exercise and protein intake, we cannot state that these are not important in explaining fatigue differences between dialysis and non-dialysis days. Prior studies reported significant variations in exercise and nutritional status on dialysis days compared to non-dialysis days $[6,31]$. Fourth, we did not collect any laboratory or clinical parameters during the non-dialysis day which precludes precise association with and comparison of fatigue characteristics between dialysis and non-dialysis days. Future studies should measure these variables on both days in a larger and diverse patient sample to improve generalizability, and understand better which factors contribute to fatigue on dialysis and non-dialysis days. Inclusion of ultrafiltration, diffusion, osmotic shifts, and other intradialytic hemodynamics often implicated in post-dialysis fatigue were not investigated in the current study. They may help explain fatigue differences between dialysis and non-dialysis days.

Despite limitations, our findings may have clinical implications. Daily adequate amount of quality protein intake along with regular physical activity may alleviate fatigue burden especially on dialysis days and should be promoted by lifestyle or behavioral modifications. As mentioned, hemodialysis patients are less engaged in physical activities on dialysis days and preliminary results demonstrate that low-to-moderate-intensity exercise prior to hemodialysis is effective in improving fatigue [42]. One small-scale randomized clinical trial also demonstrated intradialytic exercise was efficacious in reducing fatigue in the intervention group compared to the control group [43]. From clinical perspectives, our results reinforce the importance of maintaining the recommend minimum target of $\mathrm{nPCR}$ of $1.2 \mathrm{~g} / \mathrm{kg} / \mathrm{day}$. Intradialytic protein intake improves $\mathrm{nPCR}$ [44] and it may be worthwhile to examine the clinical efficacy of improved nPCR in alleviating fatigue. Of note, adequate protein intake, expressed as nPCR, has an independent salutary effect on morbidity and mortality in hemodialysis patients despite maintaining adequate dialysis dose [45]. It is unknown if clinical management of depression would be efficacious to relieve fatigue severity. It has been shown, however, that anti-depressant medication leads to a significant improvement in nPCR level and is effective in treating depression in hemodialysis patients [46]. Our findings may improve the understanding of fatigue toward the development of reliable fatigue measurement scale for clinical use. These results may also pave the way for the development of guidelines to define and manage fatigue in hemodialysis patients.

\section{Conclusions}

This study extends our current knowledge of the nature of fatigue by demonstrating its characteristics on both dialysis and non-dialysis days. Our results show that fatigue severity and the negative impact of fatigue on daily activities - general activity, mood, walking ability, normal work, relations with other people, and enjoyment of life - were remarkably pronounced on a dialysis day compared to a non-dialysis day. In addition, severe fatigue was highly prevalent on a dialysis day. The study shows significant relationships between fatigue and physical activity, nutritional status, and depression, but these correlates do not explain differences in fatigue between dialysis and non-dialysis days in the patient cohort we studied and further research is needed. These findings may help both clinical trialists and researchers design experiments and trials with targeted and timely interventions leading to improved fatigue management in hemodialysis patients.

\section{Acknowledgements \\ The authors are grateful to the dialysis center nursing staff and the patients for their cooperation.}

\section{Authors' contributions}

Research idea and study design: SD; data acquisition: SD, RR; data analysis and interpretation: SD, SB, BSK, CL, KS; statistical analysis: CL, SD. Each author contributed important intellectual content during manuscript drafting or revision. All authors have approved the final version of the manuscript. The authors read and approved the final manuscript.

\section{Funding}

This work was partially supported by the San Antonio Area Foundation. Funding source had role in data interpretations.

Availability of data and materials

The datasets generated and/or analyzed during the current study are not publicly available because the study is not federally funded and study 
activities are ongoing and data are being analyzed; however, data may be available from the corresponding author on reasonable request.

\section{Declarations}

\section{Ethics approval and consent to participate}

The study protocol was approved by the Institutional Research Board at the University of Texas Health San Antonio (Protocol Number: HSC20110429H). The study was performed in accordance with the Declaration of Helsinki. Written informed consent was obtained from each participant prior to study procedures.

\section{Consent for publication}

Not applicable.

\section{Competing interests}

The authors declare that they have no competing interests.

\section{Author details}

'Division of Nephrology, Department of Medicine, University of Texas Health San Antonio, 7703 Floyd Curl Dr, San Antonio, TX, USA. ${ }^{2}$ University Health, 4502 Medical Dr, San Antonio, TX, USA. ${ }^{3}$ Division of Clinical Immunology, Department of Medicine, University of Texas Health San Antonio, 7703 Floyd Curl Dr, San Antonio, TX, USA.

\section{Received: 20 January 2021 Accepted: 15 March 2021}

\section{Published online: 27 March 2021}

\section{References}

1. Almutary $\mathrm{H}$, Bonner A, Douglas C. Which patients with chronic kidney disease have the greatest symptom burden? A comparative study of advanced CKD stage and dialysis modality. J Ren Care. 2016;42(2):73-82. https://doi.org/10.1111/jorc.12152.

2. Jacobson J, Ju A, Baumgart A, Unruh M, O'Donoghue D, Obrador G, et al. Patient perspectives on the meaning and impact of fatigue in hemodialysis: a systematic review and thematic analysis of qualitative studies. Am J Kidney Dis. 2019;74(2):179-92. https://doi.org/10.1053/j.ajkd.2019.01.034.

3. Caplin B, Kumar S, Davenport A. Patients' perspective of haemodialysisassociated symptoms. Nephrol Dial Transplant. 2011;26(8):2656-63. https:// doi.org/10.1093/ndt/gfq763.

4. Flythe JE, Dorough A, Narendra JH, Forfang D, Hartwell L, Abdel-Rahman E. Perspectives on symptom experiences and symptom reporting among individuals on hemodialysis. Nephrol Dial Transplant. 2018;33(10):1842-52. https://doi.org/10.1093/ndt/gfy069.

5. Ramkumar N, Beddhu S, Eggers P, Pappas LM, Cheung AK. Patient preferences for in-center intense hemodialysis. Hemodial Int. 2005;9(3):28195. https://doi.org/10.1111/j.1492-7535.2005.01143.x.

6. Burrowes JD, Larive B, Cockram DB, Dwyer J, Kusek JW, McLeroy S, et al. Effects of dietary intake, appetite, and eating habits on dialysis and nondialysis treatment days in hemodialysis patients: cross-sectional results from the HEMO study. J Ren Nutr. 2003;13(3):191-8. https://doi.org/10.1016/s1 051-2276(03)00069-4.

7. Song M, Gilet CA, Lin F, MacHardy N, DeVitoDabbs AJ, Fine JP, et al. Characterizing daily life experience of patients on maintenance dialysis. Nephrol Dial Transplant. 2011;26(11):3671-7. https://doi.org/10.1093/ndt/ gfr071.

8. Williams MA, Sklar AH, Burright RG, Donovick PJ. Temporal effects of dialysis on cognitive functioning in patients with ESRD. Am J Kidney Dis. 2004;43(4): 705-11. https://doi.org/10.1053/j.ajkd.2003.12.031.

9. Zhang H, Schaubel DE, Kalbfleisch JD, Bragg-Gresham JL, Robinson BM, Pisoni RL, et al. Dialysis outcomes and analysis of practice patterns suggests the dialysis schedule affects day-of-week mortality. Kidney Int. 2012;81(11): 1108-15. https://doi.org/10.1038/ki.2011.481.

10. Ju A, Unruh ML, Davison SN, Dapueto J, Dew MA, Fluck R, et al. Patientreported outcome measures for fatigue in patients on hemodialysis: a systematic review. Am J Kidney Dis. 2018;71(3):327-43. https://doi.org/10.1 053/j.ajkd.2017.08.019.

11. Abdel-Kader K, Jhamb M, Mandich LA, Yabes J, Keene RM, Beach S, et al. Ecological momentary assessment of fatigue, sleepiness, and exhaustion in ESKD. BMC Nephrol. 2014;15(1):29. https://doi.org/10.1186/1471-2369-15-29.
12. Horigan $A E$, Barroso JV: A comparison of temporal patterns of fatigue in patients on hemodialysis. Nephrol Nurs J 2016;43(2):129-138, 148; quiz 139.

13. Ju A, Unruh M, Davison S, Dapueto J, Dew MA, Fluck R, et al. Establishing a Core outcome measure for fatigue in patients on hemodialysis: a standardized outcomes in nephrology-hemodialysis (SONG-HD) consensus workshop report. Am J Kidney Dis. 2018;72(1):104-12. https://doi.org/10.1 053/j.ajkd.2017.12.018.

14. Picariello F, Moss-Morris R, Macdougall IC, Chilcot AJ. The role of psychological factors in fatigue among end-stage kidney disease patients: a critical review. Clin Kidney J. 2017;10(1):79-88. https://doi. org/10.1093/ckj/sfw113.

15. Jhamb M, Weisbord SD, Steel JL, Unruh M. Fatigue in patients receiving maintenance dialysis: a review of definitions, measures, and contributing factors. Am J Kidney Dis. 2008;52(2):353-65. https://doi.org/10.1053/j.ajkd.2 008.05.005.

16. Flythe JE, Hilliard T, Lumby E, Castillo G, Orazi J, Abdel-Rahman EM, et al. Fostering innovation in symptom management among hemodialysis patients: paths forward for insomnia, muscle cramps, and fatigue. Clin J Am Soc Nephrol. 2019;14(1):150-60. https://doi.org/10.2215/CJN.07670618.

17. Beck AT, Ward CH, Mendelson M, Mock J, Erbaugh J. An inventory for measuring depression. Arch Gen Psychiatry. 1961;4(6):561-71. https://doi. org/10.1001/archpsyc.1961.01710120031004.

18. Kondo K, Antick JR, Ayers CK, Kansagara D, Chopra P. Depression screening tools for patients with kidney failure: a systematic review. Clin J Am Soc Nephrol. 2020;15(12):1785-95. https://doi.org/10.2215/CJN.05540420.

19. Mendoza TR, Wang XS, Cleeland CS, Morrissey M, Johnson BA, Wendt JK, et al. The rapid assessment of fatigue severity in cancer patients: use of the brief fatigue inventory. Cancer. 1999;85(5):1186-96. https://doi.org/10.1002/ (sici)1097-0142(19990301)85:53.0.c0;2-n.

20. Leinau L, Murphy TE, Bradley E, Fried T. Relationship between conditions addressed by hemodialysis guidelines and non-ESRD-specific conditions affecting quality of life. Clin J Am Soc Nephrol. 2009;4(3):572-8. https://doi. org/10.2215/CJN.03370708

21. Eriguchi R, Obi Y, Streja E, Tortorici AR, Rhee CM, Soohoo M, et al. Longitudinal associations among renal urea clearance-corrected normalized protein catabolic rate, serum albumin, and mortality in patients on hemodialysis. Clin J Am Soc Nephrol. 2017;12(7):1109-17. https://doi.org/1 $0.2215 /$ CJN.13141216

22. Hasegawa J, Kimachi M, Kurita N, Kanda E, Wakai S, Nitta K. The normalized protein catabolic rate and mortality risk of patients on hemodialysis by frailty status: the Japanese Dialysis outcomes and practice pattern study. J Ren Nutr. 2020;30(6):535-9. https://doi.org/10.1053/j.jrn.2019.12.005.

23. Jindal KK, Goldstein MB. Urea Kinetic Modelling in Chronic Hemodialysis: Benefits, Problems, and Practical Solutions. Semin Dial. 1988;1(2):82-5. https://doi.org/10.1111/j.1525-139X.1988.tb00710.x.

24. Brys ADH, Lenaert B, Van Heugten CM, Gambaro G, Bossola M: Exploring the Diurnal Course of Fatigue in Patients on Hemodialysis Treatment and Its Relation With Depressive Symptoms and Classical Conditioning. J Pain Symptom Manage 2019; 57(5): 890-898.e4 DOl: https://doi.org/10.1016/j.jpa insymman.2019.02.010

25. Moskowitz DS, Young SN. Ecological momentary assessment: what it is and why it is a method of the future in clinical psychopharmacology. J Psychiatry Neurosci. 2006;31(1):13-20.

26. Potts C, Bond R, Ryan A, Mulvenna M, McCauley C, Laird E, et al. Ecological momentary assessment within a digital health intervention for reminiscence in persons with dementia and caregivers: user engagement study. JMIR mHealth uHealth. 2020;8(7):e17120. https://doi.org/10.2196/17120.

27. Bossola M, Vulpio C, Tazza L. Fatigue in chronic dialysis patients. Semin Dial. 2011;24(5):550-5. https://doi.org/10.1111/j.1525-139X.2011.00956.x.

28. Horigan AE. Fatigue in hemodialysis patients: a review of current knowledge. J Pain Symptom Manag. 2012:44(5):715-24. https://doi.org/10.1 016/j.jpainsymman.2011.10.015.

29. Delgado C, Johansen KL. Barriers to exercise participation among dialysis patients. Nephrol Dial Transplant. 2012;27(3):1152-7. https://doi.org/10.1093/ ndt/gfr404.

30. Goodman ED, Ballou MB. Perceived barriers and motivators to exercise in hemodialysis patients. Nephrol Nurs J. 2004;31(1):23-9.

31. Yamamoto $S$, Matsuzawa R, Hoshi $K$, Harada M, Watanabe T, Suzuki Y, et al. Impact of physical activity on Dialysis and nondialysis days and clinical outcomes among patients on hemodialysis. J Ren Nutr. 2020. https://doi. org/10.1053/j.jrn.2020.07.007. 
32. Evans N, Forsyth E. End-stage renal disease in people with type 2 diabetes: systemic manifestations and exercise implications. Phys Ther. 2004;84(5): 454-63. https://doi.org/10.1093/ptj/84.5.454.

33. Kopple JD. National kidney foundation $\mathrm{K} / \mathrm{DOQ}$ clinical practice guidelines for nutrition in chronic renal failure. Am J Kidney Dis. 2001;37(1 Suppl 2):66S70. https://doi.org/10.1053/ajkd.2001.20748.

34. Ikizler TA, Burrowes JD, Byham-Gray LD, Campbell KL, Carrero J, Chan W, et al. KDOQI clinical practice guideline for nutrition in CKD: 2020 update. Am J Kidney Dis. 2020;76(3 Suppl 1):S1-S107. https://doi.org/10.1053/j.ajkd.2 020.05.006.

35. Kodama H, Togari T, Konno Y, Tsuji A, Fujinoki A, Kuwabara S, et al. A new assessment scale for post-dialysis fatigue in hemodialysis patients. Ren Replace Ther. 2020;6(1). https://doi.org/10.1186/s41100-019-0252-5.

36. Artom M, Moss-Morris R, Caskey F, Chilcot J. Fatigue in advanced kidney disease. Kidney Int. 2014:86(3):497-505. https://doi.org/10.1038/ki.2014.86

37. Gordijn MC, Beersma DG, Bouhuys AL, Reinink E, Van den Hoofdakker RH. a longitudinal study of diurnal mood variation in depression; characteristics and significance. J Affect Disord. 1994;31(4):261-73. https://doi.org/10.1016/ 0165-0327(94)90102-3.

38. Debnath S, Rueda R, Bansal S, Sharma K, Lorenzo C. Assessment of fatigue in hemodialysis patients: performance of the brief fatigue inventory. Gen Hosp Psychiatry. 2020;68:115-7. https://doi.org/10.1016/j.genhosppsych.202 0.08.006.

39. Ju A, Teixeira-Pinto A, Tong A, Smith AC, Unruh M, Davison SN, et al. Validation of a Core patient-reported outcome measure for fatigue in patients receiving hemodialysis: the SONG-HD fatique instrument. Clin J Am Soc Nephrol. 2020;15(11):1614-21. https://doi.org/10.2215/CJN.05880420.

40. Yoshino M, Kuhlmann MK, Kotanko P, Greenwood RN, Pisoni RL, Port FK, et al. International differences in dialysis mortality reflect background general population atherosclerotic cardiovascular mortality. J Am Soc Nephrol. 2006;17(12):3510-9. https://doi.org/10.1681/ASN.2006020156.

41. Jhamb M, Pike F, Ramer S, Argyropoulos C, Steel J, Dew MA, et al. Impact of fatigue on outcomes in the hemodialysis (HEMO) study. Am J Nephrol. 2011;33(6):515-23. https://doi.org/10.1159/000328004.

42. Maniam R, Subramanian P, Singh SKS, Lim SK, Chinna K, Rosli R. Preliminary study of an exercise programme for reducing fatigue and improving sleep among long-term haemodialysis patients. Singapore Med J. 2014;55(9):47682. https://doi.org/10.11622/smedj.2014119.

43. Salehi F, Dehghan M, Mangolian Shahrbabaki P, Ebadzadeh MR. Effectiveness of exercise on fatigue in hemodialysis patients: a randomized controlled trial. BMC Sports Sci Med Rehabil. 2020;12(1):19. https://doi.org/1 0.1186/s13102-020-00165-0

44. Caetano C, Valente A, Silva FJ, Antunes J, Garagarza C. Effect of an intradialytic protein-rich meal intake in nutritional and body composition parameters on hemodialysis patients. Clin Nutr ESPEN. 2017;20:29-33. https://doi.org/10.1016/..clnesp.2017.04.003.

45. Kalantar-Zadeh K, Supasyndh O, Lehn RS, McAllister CJ, Kopple JD. Normalized protein nitrogen appearance is correlated with hospitalization and mortality in hemodialysis patients with $\mathrm{Kt} / \mathrm{N}$ greater than 1.20 . J Ren Nutr. 2003;13(1):15-25. https://doi.org/10.1053/iren.2003.50005.

46. Koo J, Yoon J, Joo M, Lee H, Oh J, Kim S, et al. Treatment of depression and effect of antidepression treatment on nutritional status in chronic hemodialysis patients. Am J Med Sci. 2005;329(1):1-5. https://doi.org/10. 097/00000441-200501000-00001.

\section{Publisher's Note}

Springer Nature remains neutral with regard to jurisdictional claims in published maps and institutional affiliations.

Ready to submit your research? Choose BMC and benefit from:
- fast, convenient online submission
- thorough peer review by experienced researchers in your field
- rapid publication on acceptance
- support for research data, including large and complex data types
- gold Open Access which fosters wider collaboration and increased citations
- maximum visibility for your research: over 100M website views per year
At BMC, research is always in progress.
Learn more biomedcentral.com/submissions

